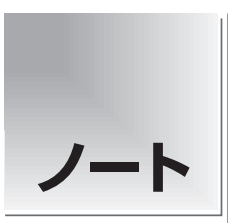

論文受付

2013 年 7 月 10 日

論文受理

2014 年 6 月 24 日

Code No. 431

\section{VMAT におけるダイナミックパラメータが 線量処方精度に与える影響について}

がん研究会有明病院放射線治療部

\section{緒 言}

近年，強度変調回転照射(volumetric modulated arc therapy: VMAT)が臨床利用され始めてきている。この 照射方法は回転照射を基本として，照射中に multi-leaf collimator(MLC)の開口形状やガントリ回転速度 (gantry speed: GS), 線量率(dose-rate: DR)をダイナミックに変 化させる照射方法である。 VMATでは，コントロール ポイントごとに MLCの開口形状や GS, DRの計算が 実施されて，それを基にダイナミック照射の制御を行 う。従来の固定多門の強度変調放射線治療(intensity modulated radiation therapy: IMRT) と比較して照射時 間の短縮化が可能になり，スループットの向上が期待 できる。

Sliding window 法を用いたIMRT においては，ビー
ムが出力されている間に MLC がダイナミックに動作し て照射を行う。VMATでは MLCに加えて GS や DR も ダイナミックに動作するため, ダイナミックパラメータ (dynamic parameter: DP)の動作精度やそれらが線量処 方に与える影響を評価する必要がある。VMATにおけ る機器動作精度について, 佐々木らはログファイルを使 用してDPの動作精度を確認している ${ }^{1)}$ 。また, Elekta 社のVMATにおいては, Hagaらが照射によって得ら れたログファイルを用いて線量再構成を行い, 線量処 方精度を検証した例を報告している22．ほかにもVMAT における機器動作精度や線量処方精度に関する報告が あるものの ${ }^{3)}$, DP が線量処方に与える影響について， 測定を通して評価している報告は少ない。本研究の目 的は, VMAT 特有の DP が線量処方精度に与える影響

\title{
Impact of Dynamic Parameters on Dose Delivery Accuracy in Volumetric Modulated Arc Therapy
}

Fumiyasu Matsubayashi,* Ryo Takahashi, Yasushi Ito, Takeo Hashimoto, Satoko Saotome, and Tomoharu Sato

Department of Radiation Therapy, Cancer Institute Hospital

Received July 10, 2013; Revision accepted June 24, 2014

Code No. 431

\section{Summary}

Volumetric modulated arc therapy (VMAT) is an irradiation method in which the multi-leaf collimator (MLC) shape, gantry speed and dose-rate is continuously varied. Gantry speed and dose-rate are treated as specific dynamic parameters (DPs) in VMAT, so there is a need to confirm the influence of DPs on dose distribution. The purpose of this study was to verify the impact of DPs on the accuracy of dose delivery in VMAT. We adopted an irradiation scenario in which DPs were modified from the original plan without making any changes in the dose distribution. We carried out irradiation and measured the dose distributions using a Delta4 diode array phantom, during which we acquired log files that enabled us to calculate DPs. The results showed that dose errors exceeding $1 \%$ or geometric errors greater than $1 \mathrm{~mm}$ were not produced by modifying the DPs. We were therefore able to verify the impact of DPs on dose delivery accuracy in VMAT.

Key words: volumetric modulated arc therapy, gantry speed, dose-rate, dynamic parameters, prescription accuracy

*Proceeding author 
Table 1 Dose constraint protocol used for the treatment and summary of dose volume parameters

\begin{tabular}{|c|c|c|c|c|c|c|c|}
\hline Structure or organ & $\begin{array}{c}\text { Dose volume } \\
\text { parameter }\end{array}$ & $\begin{array}{l}\text { Limit of dose } \\
\text { or Volume }\end{array}$ & Case 1 & Case2 & Case 3 & Case4 & Case 5 \\
\hline PTV for prostate & D95 & $56.0 \mathrm{~Gy}$ & $56.0 \mathrm{~Gy}$ & $56.0 \mathrm{~Gy}$ & $56.0 \mathrm{~Gy}$ & $56.0 \mathrm{~Gy}$ & $56.0 \mathrm{~Gy}$ \\
\hline \multirow[t]{3}{*}{ and seminal vesicle } & D99 & $\geq 53.2 \mathrm{~Gy}$ & $54.9 \mathrm{~Gy}$ & $54.9 \mathrm{~Gy}$ & $53.9 \mathrm{~Gy}$ & $55.0 \mathrm{~Gy}$ & $54.9 \mathrm{~Gy}$ \\
\hline & maximum & $\leq 64.4 \mathrm{~Gy}$ & $61.0 \mathrm{~Gy}$ & $60.2 \mathrm{~Gy}$ & $63.0 \mathrm{~Gy}$ & $59.8 \mathrm{~Gy}$ & $59.7 \mathrm{~Gy}$ \\
\hline & mean & $\leq 60.5 \mathrm{~Gy}$ & $57.8 \mathrm{~Gy}$ & $57.4 \mathrm{~Gy}$ & $58.7 \mathrm{~Gy}$ & $57.5 \mathrm{~Gy}$ & $57.2 \mathrm{~Gy}$ \\
\hline PTV for & D99 & $\geq 53.2 \mathrm{~Gy}$ & $51.9 \mathrm{~Gy}$ & $55.3 \mathrm{~Gy}$ & $57.3 \mathrm{~Gy}$ & $56.3 \mathrm{~Gy}$ & $55.8 \mathrm{~Gy}$ \\
\hline enlarged lymph node & maximum & $\leq 64.4 \mathrm{~Gy}$ & $58.9 \mathrm{~Gy}$ & $59.5 \mathrm{~Gy}$ & $61.2 \mathrm{~Gy}$ & $58.9 \mathrm{~Gy}$ & $59.1 \mathrm{~Gy}$ \\
\hline PTV for & D99 & $\geq 47.9 \mathrm{~Gy}$ & $49.8 \mathrm{~Gy}$ & $47.9 \mathrm{~Gy}$ & $50.2 \mathrm{~Gy}$ & $49.4 \mathrm{~Gy}$ & $49.7 \mathrm{~Gy}$ \\
\hline \multicolumn{8}{|l|}{ subclinical lymph node } \\
\hline \multirow[t]{4}{*}{ Rectum wall } & V40 & $<60 \%$ & $26.0 \%$ & $26.5 \%$ & $28.7 \%$ & $31.3 \%$ & $35.6 \%$ \\
\hline & V60 & $<35 \%$ & $0.0 \%$ & $0.0 \%$ & $0.0 \%$ & $0.0 \%$ & $0.0 \%$ \\
\hline & V70 & $<25 \%$ & $0.0 \%$ & $0.0 \%$ & $0.0 \%$ & $0.0 \%$ & $0.0 \%$ \\
\hline & V78 & $<2 \%$ & $0.0 \%$ & $0.0 \%$ & $0.0 \%$ & $0.0 \%$ & $0.0 \%$ \\
\hline Small bowel & V60 & $<0.5 \mathrm{cc}$ & $0.0 \mathrm{cc}$ & $0.0 \mathrm{cc}$ & $0.0 \mathrm{cc}$ & $0.0 \mathrm{cc}$ & $0.0 \mathrm{cc}$ \\
\hline \multirow[t]{2}{*}{ Bladder wall } & V40 & $<60 \%$ & $71.3 \%$ & $51.2 \%$ & $63.4 \%$ & $46.5 \%$ & $48.0 \%$ \\
\hline & V70 & $<35 \%$ & $0.0 \%$ & $0.0 \%$ & $0.0 \%$ & $0.0 \%$ & $0.0 \%$ \\
\hline
\end{tabular}

について，測定を基に明らかにすることである.

\section{1. 方 法}

本研究の対象は，所属リンパ節に転移を認める前立 腺癌に対する骨盤照射のVMAT プラン 5 例である。 な 押, 本研究は当施設の臨床研究倫理審査委員会の承認 を受けて実施し，画像などの患者個人情報はすべて匿 名化して解析に用いた。

リニアックは Clinac 21EX(Varian Medical Systems 社 製)を使用した．X 線のエネルギーを $10 \mathrm{MV}$ とし，ガン トリ回転角度は 179 度から 181 度までの 358 度として, 時計回りと反時計回りの 2 アークのプランとした. 線量 率の上限值である設定線量率(nominal dose rate: NDR) は 600 モニタユニット(monitor unit: MU)/min に設定 し,コリメータは 20 度回転させた。

治療計画はEclipse version 10(Varian Medical Systems 社製)を用いて行った. Simultaneous integrated boost $(\mathrm{SIB})$ 法を使用し, 28 回の照射に扔いて前立腺と 精囊, ならびに転移リンパ節に対する planning target volume (PTV)の 95\%容積をカバーする線量(D95)を $56 \mathrm{~Gy}$ ，領域リンパ節に対するPTVのD95を 50.4 Gy になるように計画を立案した。リスク臟器には直腸，小 腸, 膀胱を設定した，最適化計算においては，コント ロールポイントをそれぞれのアークで 177 個に設定し,

MLC の最大速度は $2.5 \mathrm{~cm} / \mathrm{s}$ に設定した，線量計算は anisotropic analytical algorithm(AAA)法で実施した。 当 院における PTV やリスク臟器の線量制約值と, 作成し たプランの結果を Table 1 に示す。 なお，当施設では対
象症例に対して骨盤照射を実施したのち，PTV を前立 腺と精囊に限局して $22 \mathrm{~Gy}, 11$ 回分割のブースト照射 を実施している。したがって, 最終的な線量制約值は ブースト照射を考慮して評価している.

次いで,オリジナルのプランを基とした GS や DR の 変更プラン $\left(P_{\text {modi }}\right)$ を作成した. Eclipse version 10 では GS や DR を任意の值に設定することは不可能である. 一方で, NDR を変化させることは可能であり, それを 変化させると線量分布や単位角度ごとの MU 值を保持 したままで, GS や DR が変化するプランを作成可能 である，本研究では，オリジナルのプランの NDRを $100 \mathrm{MU} / \mathrm{min}$ ごとに $100 \mathrm{MU} / \mathrm{min}$ まで変化させることに よって GS や DR を変化させて, DP の変化を作り出し た．NDR を変化させたときの GS や DR の変化を Fig. 1 に示す． $P_{\text {modi }}$ はガントリ回転角度が 358 度であるた め, 治療寝台にX 線が当たることを避けるのは不可能 である。したがって，治療計画において仮想寝台を用 いることで寝台によるX 線の減弱を考慮した。

測定はDelta4(Scandidos 社製)を用いて実施した. Delta4 の表面に印字されているマークを利用して検出 器をアイソセンタに設置し, 位置を固定してすべての測 定を行った。 $P_{\operatorname{modi}}$ の測定に先立って, Delta4の線量 率依存性を確認した。ガントリ角度を 0 度に設定して $10 \mathrm{~cm} \times 10 \mathrm{~cm}$ の正方形照射野を作成し，10 MV の X 線を $200 \mathrm{MU}$ 照射した. 線量率を $600 \mathrm{MU} / \mathrm{min}$ から $100 \mathrm{MU} / \mathrm{min}$ ごとに変化させたときの, 検出器中心位置での指示值 の変化を調べた，なお，Delta4には方向依存性があ り，ガントリ角度によって指示值が変化することが考え 

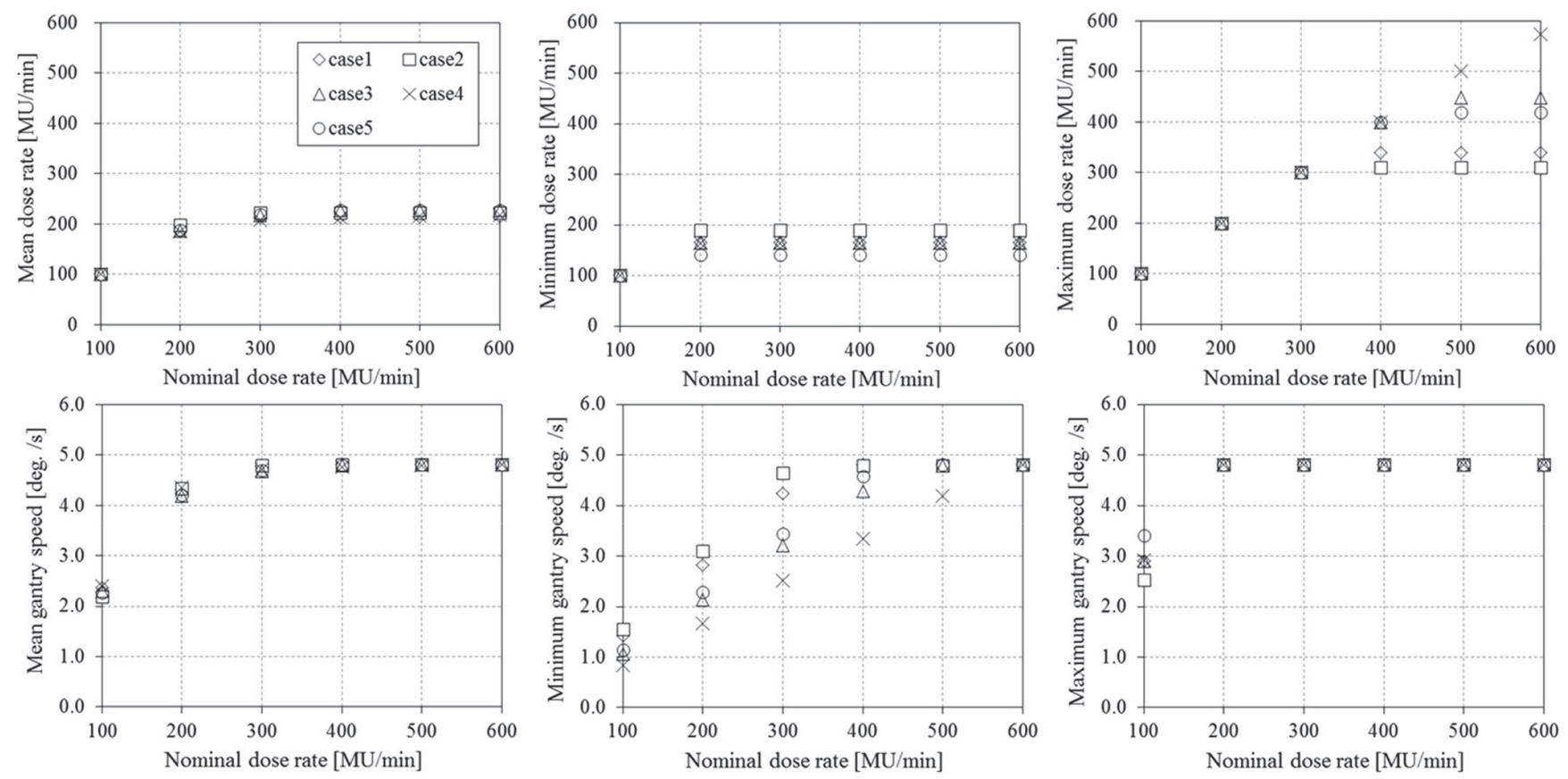

Fig. 1 Variation in dose-rate and gantry speed caused by changing nominal dose-rate.

(a) Mean dose-rate, (b) Minimum dose-rate, (c) Maximum dose-rate,

(d) Mean gantry speed, (e) Minimum gantry speed, (f) Maximum gantry speed

\begin{tabular}{l|l|l}
$a$ & $b$ & $c$ \\
\hline$d$ & $e$ & $f$
\end{tabular}

られるが，今回の評価はガントリ角度ごとの MU が変 わらないプランの実測值同士の比較であるため, 本測 定のための方向依存性の評価は行わなかった.

Delta4の基礎特性を評価したのち, $P_{\text {modi }}$ の測定を実 施して線量分布の取得を行った，得られた結果は Delta4 付属のソフトウエア (version：2011 April)で解析 し，100 MU/min を基準として NDR を変化させたとき の線量分布の違いを評価した。評価は線量差(dose difference: DD)の許容值を 1\%，位置誤差(distance to agreement: DTA)の許容值を $1 \mathrm{~mm}$, threshold $0 \%$ と したときの DD とDTAのパス率を指標とした， $P_{\text {modi }}$ を 照射する際には，MLCなどの経時的な位置情報が記録 される dynalog ファイルと，MU やガントリ角度情報が 記録される dynamic treatment $\log$ ファイルを取得し た。取得した 2 種類のログファイルを用いて，NDRが $100 \mathrm{MU} / \mathrm{min}$ のときを基準として，それぞれのコント ロールポイントに扔ける，動作するすべての MLC 位置 や経過 MU，ガントリ角度の系統誤差 (systematic error: $\mathrm{SE})$ と偶発誤差(random error: RE)を算出した. SE は以 下の式を用いて算出した。

$S E_{n d r}=\frac{\sum_{i=1}^{n}\left(P_{i, n d r}-P_{i, 100}\right)}{n}$

ここで, $P_{i, n d r}$ は任意の NDR のときのコントロールポ イント $i$ におけるパラメータであり, $P_{i, 100}$ は NDRが

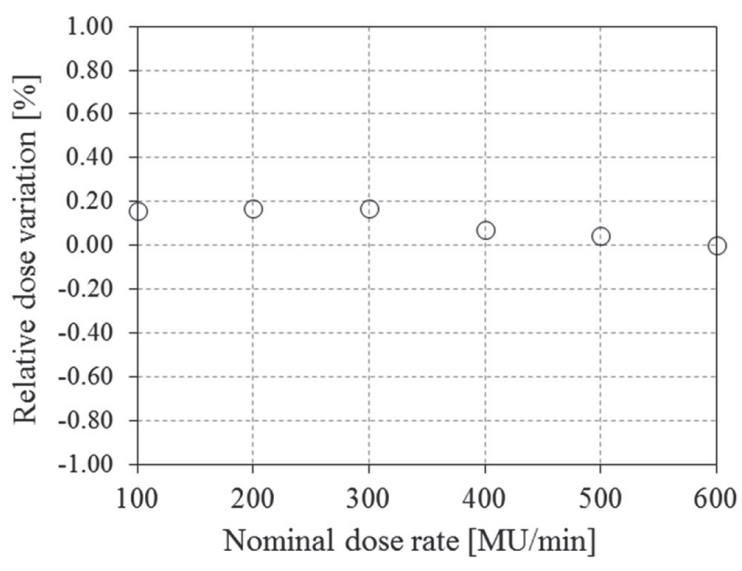

Fig. 2 Dose-rate dependency of Delta4.

The vertical axis shows relative variation of measured dose normalized by the dose when the nominal dose-rate was set at $600 \mathrm{MU} / \mathrm{min}$.

$100 \mathrm{MU} / \mathrm{min}$ のときのコントロールポイント $i$ におけるパ ラメータである. $n$ はコントロールポイントを示す，RE は以下の式を用いて算出した。

$R E_{n d r}=\sqrt{\frac{\sum_{i=1}^{n}\left[\left(P_{i, n d r}-P_{i, 100}\right)-S E_{n d r}\right]^{2}}{n}}$

\section{2. 結 果}

Delta4 の線量率依存性の測定結果を Fig. 2 に示す. 線量率 $600 \mathrm{MU} / \mathrm{min}$ での測定線量を基準としたとき, 
Table 2 Pass rate of DD and DTA under the criteria of $1 \%$ and $1 \mathrm{~mm}$

\begin{tabular}{cccccccc}
\hline \hline \multirow{2}{*}{ Case } & & \multicolumn{5}{c}{ Nominal dose rate (MU/min) } \\
\cline { 3 - 7 } & & 600 & 500 & 400 & 300 & 200 & 100 \\
\hline 1 & Pass rate (DD/DTA) (\%) & $100 / 100$ & $100 / 100$ & $100 / 100$ & $100 / 100$ & $100 / 100$ & $100 / 100$ \\
2 & Pass rate (DD/DTA) (\%) & $100 / 100$ & $100 / 100$ & $100 / 100$ & $100 / 100$ & $100 / 100$ & $100 / 100$ \\
3 & Pass rate (DD/DTA) (\%) & $100 / 100$ & $100 / 100$ & $100 / 100$ & $100 / 100$ & $100 / 100$ & $100 / 100$ \\
4 & Pass rate (DD/DTA) (\%) & $100 / 100$ & $100 / 100$ & $100 / 100$ & $100 / 100$ & $100 / 100$ & $100 / 100$ \\
5 & Pass rate (DD/DTA) (\%) & $100 / 100$ & $100 / 100$ & $100 / 100$ & $100 / 100$ & $100 / 100$ & $100 / 100$ \\
\hline
\end{tabular}
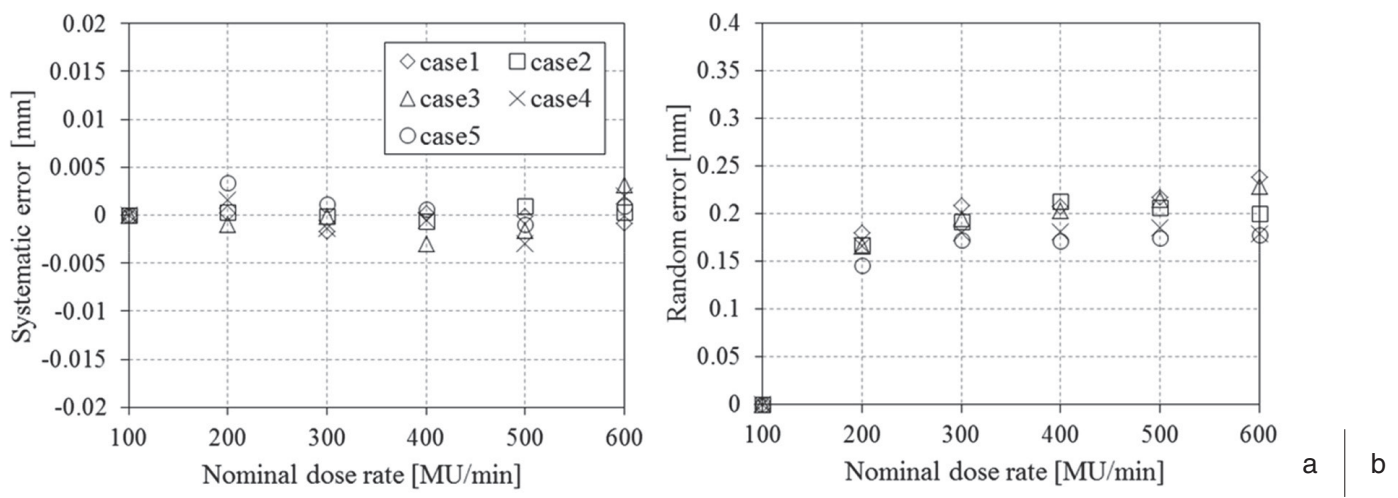

Fig. 3 Systematic error (a) and random error (b) of MLC positions.
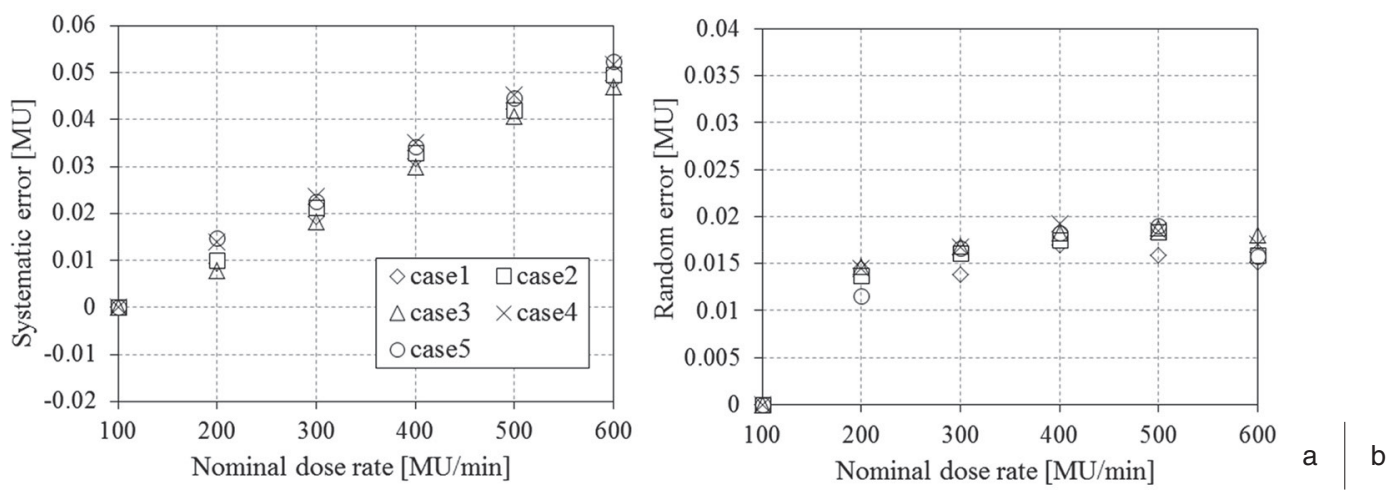

Fig. 4 Systematic error (a) and random error (b) of accumulated MU.

指示值の変化は $0.2 \%$ 以下であった.

$P_{\text {modi }}$ の測定におけるDD と DTAのパス率の変化を Table 2 に示す. パス率はすべて 100\%となった. Fig. 3 には，NDR を変化させたときの MLC 位置の SE と RE を示す．SEに大きな変化はなかったが，NDRの変化が 大きくなるとREに変化が生じ, NDRが $600 \mathrm{MU} / \mathrm{min}$ 時の RE は平均で $0.197 \mathrm{~mm}$ であった. Fig. 4 には NDR を変化させたときの経過 MU の SE とREを示す，NDR が変化しても経過 MUには大きな変化はなかった．Fig. 5 にはNDR を変化させたときのガントリ角度の SE と RE を示す，REは 0.1 度を超えることはなかった. SEはマ イナスの值となり, NDRが $600 \mathrm{MU} / \mathrm{min}$ 時は平均で 0.1 度の遅れが生じる結果となった。

\section{3. 考 察}

本検証では VMAT 特有の DP を変化させて線量分布 の測定を行った，DDやDTAの測定結果から，1\%を超 える線量差が発生することはなく，また， $1 \mathrm{~mm}$ を超え る位置誤差は発生しないことがわかった。つまり，DP に変化が生じたとしても，角度ごとの MU 值が保たれ ていれば，線量的には $1 \%$ ，幾何学的には $1 \mathrm{~mm}$ を超え る誤差を発生しないことが明らかとなった，Ling らは VMAT のコミッショニング手法を報告していて，その 中には精度試験用の照射プランを使用した DP 変化時 の線量処方精度の評価項目がある ${ }^{4}$ ，メーカが推奨する 許容值は線量差が $2 \%$ 以内となっており ${ }^{5)}$, 実際の VMAT プランを用いた本評価においても，その許容值 

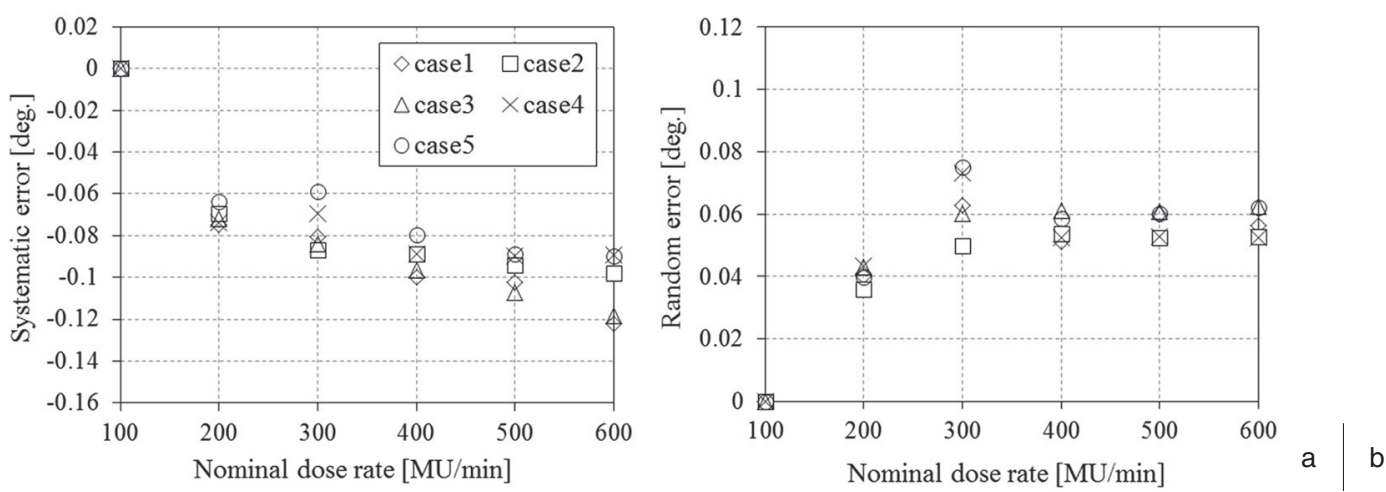

Fig. 5 Systematic error (a) and random error (b) of gantry angle.

を満たすことを確認できた。

MLC の動作精度と線量処方精度の関係性について, Oliver らは頭頸部に対するVMATにおいて MLC 位置 の系統誤差が $0.6 \mathrm{~mm}$ 変化した場合, PTVの線量指標 に $2 \%$ の変化が生じ, $5 \mathrm{~mm}$ の偶発誤差が生じても線量 指標の変化は小さいことを報告している6). また, Bai らは固定多門のIMRTに扔いて，0.5 度のガントリ角度 誤差は大きな影響を及ぼさないと報告している77。回 の測定に抢ける DP の変化は報告されている誤差量より 小さいため, $1 \%$ の線量差や $1 \mathrm{~mm}$ の位置誤差が発生し なかったと考える，上記の報告では線量再構成の手法を 用いた評価や，固定多門の IMRT による報告であるが， 本評価によって，パス率を指標とした実測を基にした VMATのDPが及ぼす影響を明らかにできたと考える。

今回の評価では，対象症例を骨盤部の VMAT とした が，他部位へのVMAT 照射や処方線量が異なる場合 は，DPの変化が本対象と異なることが考えられる，DP はログファイルなどで比較的容易に確認することが可能 であり, DPの変化量が本評価と大きく変わらなけれ ば，他部位への照射においてもDP と線量処方精度の
関係性を推定できると考える。

治療計画を行う際には，照射精度を念頭に置いてプ ランを立案する必要がある。照射精度が正しく評価さ れなければ，不必要なマージンの拡大や線量制約の変 更を招き, VMATなどの高精度放射線治療の利点を最 大限活用できないと考える。本研究はVMAT 特有の DP が線量処方精度に与える影響を実測によって明らか にしたものであり，治療計画へフィードバックするため の有用な知見を得ることができたと考える。

\section{4. 結 語}

VMAT 特有の DP が線量処方精度に与える影響を調 查した。本調査で使用した VMAT プランにおいては, DP が変化しても $1 \%$ を超える線量差や $1 \mathrm{~mm}$ を超える 幾何学的誤差は発生しないことがわかったVVMATの 線量処方精度に与える影響を実測によって明らかにす ることができた。

本研究の要旨は，第 41 回日本放射線技術学会秋季 学術大会(福岡)にて発表した。

\section{参考文献}

1）佐々木恒平，宮城結城，高倉 亨，他，Log File 用いた RapidArc 照射の精度検証．医物理 2010; 30(2): 267-268,

2) Haga A, Nakagawa K, Shiraishi K, et al. Quality assurance of volumetric modulated arc therapy using Elekta Synergy. Acta Oncol 2009; 48(8): 1193-1197.

3) Nicolini G, Clivio A, Cozzi L, et al. On the impact of dose rate variation upon RapidArc implementation of volumetric modulated are therapy. Med Phys 2011; 38(1): 264-271.

4) Ling $C C$, Zhang $P$, Archambault $Y$, et al. Commissioning and quality assurance of RapidArc radiotherapy delivery system. Int J Radiat Oncol Biol Phys 2008; 72(2): 575-581.

5) 岡本裕之. VMAT の精度管理項目. 詳説 放射線治療の精 度管理と測定技術. 中外医学社，東京，2012: 162-170.

6) Oliver M, Gagne I, Bush K, et al. Clinical significance of multi-leaf collimator positional errors for volumetric modulated arc therapy. Radiother Oncol 2010; 97(3): 554-560.

7) Bai S, Li G, Wang M, et al. Effect of MLC leaf position, collimator rotation angle, and gantry rotation angle errors on intensity-modulated radiotherapy plans for nasopharyngeal carcinoma. Med Dosim 2013; 38(2): 143-147.

問合先

干 135-8550 江東区有明 3-8-31

がん研究会有明病院放射線治療部 松林史泰 